\title{
Uncertainty Quantification in Hydrologic Predictions: A Brief Review
}

\author{
Y. R. Fan $^{1 *}$ \\ ${ }^{1}$ Department of Civil and Environmental Engineering, Brunel University London, Uxbridge, Middlesex UB8 3PH, United Kingdom
}

Received 20 October 2019; revised 15 November 2019; accepted 10 December 2019; published online 31 December 2019

\begin{abstract}
This study provides a brief review for uncertainty quantification in hydrological predictions. The major approaches for hydrologic predictions are firstly introduced, including the widely used data-driven and process-based modelling approaches. The major uncertainties resulting from inputs, model structures, parameters and outputs are then briefly illustrated. The major review is then conducted for various uncertainty quantification approaches. In detail, the approaches for quantifying uncertainties in model parameters, structures and states are mainly reviewed, such as the Markov chain Monte Carlo, sequential data assimilation and model average approaches. Potential issues to be addressed in future are then concluded, summarizing some unclear issues which may be further investigated in further studies.
\end{abstract}

Keywords: Hydrologic prediction, uncertainty quantification, Bayesian, Markov chain Monte Carlo, data assimilation

\section{Introduction}

Water resources and human being are strongly interconnected, since all aspects of our society functions are depended on water availability. Human beings rely on water for a myriad of issues, from least being requisite consumption for survival to many other socio-economic activities such as agricultural and industrial production, power generation, transportation, environmental stewardship, wildfire prevention and flood control (DeChant, 2014; Xie et al., 2018; Song et al., 2018). The water that is available for human being occurs in various forms such as rainfall, snow, rivers, lakes, groundwater, or soil moister. The total water resources in the world are estimated in the order of $43,750 \mathrm{~km}^{3} /$ year (FAO, 2003). However, extensive spatialtemporal variations exist in the distribution of water resources.

The water availability exhibits significant spatial variations from both a global scale and a territory or local scale. For instance, the islands and coastal areas near the equator usually experience a tropical marine climate with the annual rainfall being 1,000 to over $1,500 \mathrm{~mm}$; conversely, the annual precipitation in the areas of North Africa is less than $250 \mathrm{~mm}$ and even zero in some years, which cannot sustain the survival for any vegetation. Even within a territory, the water resources availability may present obvious spatial variation. The South-to-North Water Diversion Project, advocated by Chinese government is a famous project to alleviate the severe spatial unbalance of water resources in China, in which fresh water from the Yangtze River in southern China is diverted to the Yellow River and Beijing.

${ }^{*}$ Corresponding author. Tel.: +44 1895265717.

E-mail address: yurui.fan@brunel.ac.uk (Y. R. Fan).

ISSN: 2663-6859 print/2663-6867 online

(C) 2019 ISEIS All rights reserved. doi:10.3808/jeil.201900019.
In addition to severe spatial unbalance in water resources, the water resources availability also experiences serious temporal variation due to anthropogenic impacts and climate variability. For example, the annual precipitation trends in China for the period $1960 \sim 2006$ were found to decrease in northeastern area caused by the decrease in summer and autumn precipitation, increase in southeastern area resulting from the increase in summer and winter precipitation (Piao et al., 2010). Moreover, most areas all over the world usually experience wet and dry seasons for precipitation within a year, which lead to flooding and drought periods for the rivers. For instance, the Yellow River in China can have a maximum discharge of $25,000 \mathrm{~m}^{3} / \mathrm{s}$ in Summer, while it would run dry before reaching the sea in Spring since 1972.

Moreover, the temporal-spatial variations in water resources distribution are intensified due to human interventions and climate change. Studies have stated that global warming due to increased greenhouse gas emissions leads to changes in the distribution of water resources over many regions, and the global and regional hydrological cycles have been greatly influenced by climate change in the past century (Brutsaert and Palange, 1998; Scanlon et al., 2007; Solomon et al., 2007; Hagemann et al., 2013; Liu et al., 2018a, 2018b). Furthermore, humans directly change the dynamics of the water cycle through dams constructed for water storage, and through water with-drawals for industrial, agricultural or domestic purposes (Haddeland et al., 2014). The study proposed by Nakayama and Shankman (2013) predicted that the Three-Gorges Dam (TGD) would increase flood risk during the early summer monsoon against the original justifications for building the dam, relating to complex river-lake-groundwater interactions (Zhang et al., 2019).

Due to the spatial-temporal variations in water resources, 
forecasting of water flows and storage at different spatiotemporal scales concerns many water resources planners, and other related stockholders. Consequently, it is desirable to develop advanced hydrologic forecasting techniques to produce accurate predictions for hydrological discharges and other states (e.g. soil moisture).

\section{Methods for Hydrological Prediction}

There are amounts of approaches for hydrological prediction. In general, these approaches can be categorized into two groups: process-driven methods and data-driven methods (Wang, 2006). The data-driven models can capture the mapping between input (e.g. rainfall, evaporation, temperature, etc.) and output (i.e. streamflow) variables without considering the physical laws that underline the rainfall-runoff process (Wu, 2010). There are numerous data-driven modeling techniques for the forecast and simulation of streamflow series. One of the major data-driven approaches is based on statistical regression, which mainly includes multiple linear regression (Adamowski and Karapataki, 2008; Sadri and Burn, 2012; Sachindra et al., 2013) and nonlinear regression approaches (Adamowski et al., 2012). However, MLR methods have some disadvantages such as not fitting the observed data very well or diverting from tails in skewed data (Haghighatjou et al., 2008). Moreover, due to the advancement of computer science, many artificial intelligence and machine learning approaches have been developed for hydrological predictions, such as generalized regression neural network (GRNN) (Cigizoglu, 2005), feed forward back propagation neural networks (Turan and Yurdusev, 2009; Wang et al., 2009), support vector machine (Sujay Raghavendra and Deka, 2014), and least squares support vector machines (Okkan and Serbes, 2012). The AI-based models confront some drawbacks, such as possibility of getting trapped in local minima, over training, subjectivity in the determining of model parameters, initialization of the weights in each simulation randomly, and the components of its complex structure (Okkan and Serbes, 2012). In addition, there are also some nonparametric statistical approaches for hydrological predictions. Among them, the stepwise cluster analysis (SCA) method has been widely used for many hydrological applications such as streamflow predictions (Fan et al., 2015a, 2016a, b; Li et al., 2015, 2016), climate downscaling (Wang et al., 2013; Zhuang et al., 2018). The main advantage of SCA is that the inherent relationship between the explanatory and response variables is reflected through cluster trees, which are derived through cutting or merging the sample sets of response variables into new sets based on given criteria. These cluster trees, instead of specific mathematical functions, can establish the relationship between explanatory variables to response variables.

Compared with the data-driven methods, the process-based modeling approaches aim to forecast the streamflow of a river based on those physical laws in the water cycle system. The typical process-based modeling approaches are various forms of rainfall-runoff models. Although advanced data-driven models, including artificial intelligence, statistical and machine learning models have been developed by many researches, and produced high accuracy of streamflow forecasting, conceptual or process- based hydrological models are typically employed for operational flow forecasting. The process-based hydrologic models are simplified, conceptual representations of a part of the hydrologic cycle, which use relatively simple mathematical equations to conceptualize and aggregate the complex, spatially distributed, and highly interrelated water, energy, and vegetation processes in a watershed (Vrugt et al., 2005). Such process-based models are generally on the basis of mass and energy conservation. The simplest hydrologic models just consider the conceptualization of water balance (Boyle et al., 2000). However, both the water and energy balance are under consideration for most recently developed hydrologic models, due to the phase changes of water experienced above and below the earth's surface (Gao et al., 2010; DeChant, 2014). Due to the differences in perceptualization and understandings of hydrologists for different watersheds, the hydrologic models can have various formats, from physically-based (white-box) to black-box or empirical and to conceptual models, and the most distinctive, from lumped models to distributed models (Clarke, 1973; Beven, 1985; Wheater et al., 1993; Refsgaard, 1995; Beven, 2001; Moradkhani and Sorooshian, 2008). In lumped models, the entire river basin is taken as one unit where spatial variability is disregarded and thus such a modeling approach tries to relate the forcing data, mainly precipitation inputs, to system outputs (streamflow) without considering the spatial processes, patterns and organization of the characteristics governing the processes (Moradkhani and Sorooshian, 2008). Representative lumped hydrologic models include the Xinanjiang Model (Zhao, 1992), Sacramento Soil Moisture Accounting Model (SAC-SMA) (Burnash, 1995), Hymod (Moore, 1985, 2007). In comparison with lumped hydrologic models, a distributed or semi-distributed model would take consideration of spatial variation in model variables and parameters, and thus explicitly characterize the water cycle process and patterns in a watershed (Beven, 1985; Refsgaard, 1995; Smith et al., 2004). Such a kind of hydrologic models that have been widely applied by many hydrologists mainly involves SHE (Abbott et al., 1986a, b), TOPMODEL (Beven and Kirby, 1979), MIKE SHE (Refsgaard and Storm, 1995); IHDM (Calver and Wood, 1995), SLURP (Kite, 1995).

Over the past decades, hydrologic modeling has benefited from the significant of our society, including dramatic growths in computational power, increasing availability of distributed hydrologic observations, and improved understanding of the physics and dynamics of the hydrologic system (Liu and Gupta, 2007). The growing availability of both computing power and hydrological data observed at fine spatial and temporal scales has made the application of hydrologic models an attractive option for answering many of the questions which are frequently posed to hydrologists (Montanari and Brath, 2004).

\section{Uncertainties in Hydrological Prediction}

For both data-driven and process-based modeling approaches, it appears that extensive uncertainties still exist in association with the conceptualization and aggregation of the hydrologic process, and with the measurements required for forcing and evaluating the hydrologic models. These uncertainties 
would be embodied in the complex interactive processes among water, energy and vegetation in a watershed. Uncertainty can be defined as the differences between model outputs and observed values, resulting from natural variability (unpredictable rainfall, evapotranspiration, water consumption, etc.), both known and unknown errors in the input data, the model parameters, and/or the model structures and processes (Allataifeh, 2013). Current$1 y$, characterization of various uncertainties affecting hydrologic models remains a major scientific and operational challenge (Renard et al., 2010).

In general, uncertainty in hydrologic modeling may arises from several sources: inputs, outputs, model structures, model parameters. The uncertainty in model inputs refers to sampling and measurement errors for the forcing data to drive the hydrologic model, such as uncertainties in precipitation and evapotranspiration. Precipitation uncertainty is generally considered as the most influential cause of uncertainty in flood forecasting (Moradkhani and Sorooshian, 2008). The uncertainties in model inputs result from both the precision in measurement as well as the spatial-temporal averaging of these measurements. The uncertainties involved in model outputs are subject to the rating curves inaccuracies at high and low flows, known as heteroscedasticity (variance changing) of error with respect to the magnitude of flow as opposed to homoscedasticity (constant variance) of error (Moradkhani and Sorooshian, 2008). Structural uncertainty, also known as the model uncertainty, arises from the differences in conceptualization and representation of hydrologic processes in hydrologic models. The structural uncertainty in a hydrologic model depends on the model formulation (e.g., number and connectivity of stores, choice of constitutive functions, etc), on the specific catchment, and on the spatial and temporal scale of the analysis (Renard et al., 2010). The parameters in hydrologic models can be characterized into physical and process parameters: the physical parameters are those can be measured directly from the watershed, such as, watershed area, impervious area in a watershed, local permeability obtained using core samples, fraction of vegetated area, and areal percentage of water bodies; The process parameters, on the other hand, are those which cannot be measured directly and need to be infered by indirect means, including, effective depth of soil moisture storage, effective lateral interflow, rate of drainage for hypothetical lumped storages, mean hydraulic conductivity, and surface runoff coefficient (Sorooshian and Gupta, 1995; Gupta, 1998; Moradkhani and Sorooshian, 2008). The uncertainty in hydrologic model parameters reflects the inability to specify exact values of model parameters due to finite length and uncertainties in the calibration data, imperfect process understanding, model approximations, etc. (Renard et al., 2010).

Due to the extensive uncertainties in hydrologic predictions, proper consideration and quantification of those uncertainties in hydrologic predictions have been broadly recognized to be essential for purposes of both research and operational modeling (Wagener and Gupta, 2005; Liu and Gupta, 2007). The hydrologic predictions, without consideration of the associated uncertainty, would be of limited value to real world water resources applications, such as flooding control, drought management, and reservoir operation. Consequently, effective un- certainty quantification and reduction methods are required for the applications of hydrologic models to produce reliable hydrologic forecasts.

\section{Uncertainty Quantification of Hydrologic Models}

For uncertainties exist in hydrologic models, especially for characterizing the uncertainty in model parameters, significant efforts have been contributed to the development of automatic model calibration, aiming to find a best value set for model parameters to fit the actual measured model responses. Amounts of global optimization methods have been developed in recent decades to automatic find the best values for model parameters. Commonly used optimization techniques include the shuffled complex evolution method (SCE-UA) (Duan et al., 1992), Epsilon Dominance Nondominated Sorted Genetic Algorithm-II ( $\varepsilon$-NSGAII) (Deb et al., 2002; Tang et al., 2005), Multiobjective Shuffled Complex Evolution Metropolis algorithm (MOSCEM) (Vrugt et al., 2003), multialgorithm genetically adaptive multiobjective method AMALGAM (Vrugt and Robinson, 2007), and so on.

However, there are a large number of combinations for model parameter sets in the feasible region, and thus only characterizing the "best" one may not realistic; moreover, unsuccess in parameters characterization may lead to considerable uncertainty in model outputs. Therefore, probabilistic estimation methods have been developed based on Monte Carlo procedures to resolve the above issues. Those available probabilistic methods to identify the parameter uncertainty mainly include the Generalized Likelihood Uncertainty Estimation (GLUE) method proposed by Beven and Binley (1992), the Bayesian Recursive Estimation (BaRE) algorithm developed by Thiemann et al. (2001); the Metropolis method reported by Kuczera and Parent (1998) and the Shuffled Complex Evolution Metropolis (SCEMUA) algorithm advanced by Vrugt et al. (2003). The GLUE method works based on different realization of parameter sets in order to estimate the sensitivity of model prediction to various parameter sets; the parameter sets are categorized into behavioral and non-behavioral via a likelihood measure and those that are considered as non-behavioral are discarded for prediction (Moradkhani and Sorooshian, 2008). However, previous studies indicated that the reduced capacity of this method owing to its inconsistency with the Bayesian inference process would lead to large overestimation on uncertainty, both for the parameter estimation and hydrologic forecasting (Mantovan and Todini, 2006; Moradkhani and Sorooshian, 2008). The Bayesian recursive estimation (BaRE) approach proposed by Thiemann et al. (2001) can be used for simultaneous parameter estimation and prediction in an operational setting, in which the prediction is described in terms of the probabilities associated with different output values, and the uncertainty associated with the parameter estimates is updated (reduced) recursively, resulting in smaller prediction uncertainties as measurement data are successively assimilated. The Metropolis method developed by Kuczera and Parent (1998) for the parameter uncertainty estimation employs a random walk that adapts to the true probability distribution describing parameter uncertainty. The 
SCEM-UA is the extension of the SCE-UA algorithm (Duan et al., 1992), in which the Metropolis Hastings (MH) algorithm, controlled random search (Price, 1987), competitive evolution (Holland, 1975), and complex shuffling (Duan et al., 1992) are integrated together to continuously update the proposal distribution and evolve the sampler to the posterior target distribution (Vrugt et al., 2003). In addition, the approximate Bayesian computation $(\mathrm{ABC})$ has been applied for uncertainty quantification for hydrologic models (Vrugt and Sadegh, 2014). This statistical methodology relaxes the need for an explicit likelihood function in favor of one or multiple different summary statistics rooted in hydrologic to estimate the posterior probability distributions of hydrologic model parameters (Sadegh and Vrugt, 2013, 2014).

For uncertainty in model structures, one powerful approach to deal with this problem is to use combination of multimodel predictions, or model averaging approaches. The motivating idea behind model averaging is that, with various competing models at hand, each having its own strengths and weaknesses, combination of the individual model forecasts into a single new forecast that, up to one's favorite standard, is at least as good as any of the individual forecasts (Diks and Vrugt, 2010). Commonly used model averaging techniques include equal weights averaging (EWA) where each of the available models is weighted equally (Diks and Vrugt, 2010), Bates-Granger averaging (BGA) (Bates and Granger, 1969), AIC and BIC-based model averaging (AICA and BICA, respectively) (Buckland et al. 1997; Burnham and Anderson, 2002; Hansen, 2008), Bayesian model averaging (BMA) (Raftery et al., 1997, 2005; Hoeting et al., 1999), Mallows model averaging (MMA) (Hansen, 2007, 2008). Specifically, the Bayesian model averaging method has been widely employed to account for structural uncertainty in hydrologic models. BMA predictions are weighted averages of the individual predictions from competing models, in which the weights can reflect the relative model performance since they are the probabilistic likelihood measures of a model being correct given the observations (Duan et al., 2007).

In a separate line of research, data assimilation methods, especially sequential data assimilation techniques, have been developed for explicitly dealing with various uncertainties and for optimally merging observations into uncertain model predictions (Xie and Zhang, 2013). In contrast to classical model calibration strategies, sequential data assimilation methods continuously updated the states and parameters in the model when new measurements become available to improve the model forecast and evaluate the forecast accuracy (Vrugt et al., 2005). One prototype of sequential data assimilation techniques is the celebrated Kalman filter (Kalman, 1960). For a dynamical system with linear states and measurement equations and normally distributed model errors, the Kalman filter method can provide the optimal recursive solution to the state updating problem (Moradkhani and Sorooshian, 2008). Three extensions to the KF are widely known, namely, the extended Kalman filter (EKF) (Georgakakos, 1986a, b), ensemble Kalman filter(EnKF) (Evensen, 1994) and unscented Kalman filter (UKF) (Julier and Uhlmann, 1997) to deal with nonlinearity in states and measurement equations (Liu et al., 2012). Among them, the EnKF approach is one of the most frequently used assimilation methods in hydrology, due to its attractive features of realtime adjustment and ease of implementation (Reichle et al., 2002). The EnKF is based upon Monte Carlo or ensemble generations where the approximation of the forecast state error covariance matrix is made by propagating an ensemble of model states using the updated states from the previous time step, and the key point EnKF is to generate the ensemble of observations at each update time by introducing noise drawn from a distribution with zero mean and covariance equal to the observational error covariance matrix (Moradkhani and Sorooshian, 2008). The EnKF method provides a general framework for dynamic state, parameter, as well as joint state-parameter estimation in hydrologic models and has been widely applied for uncertainty quantification of hydrologic models. For example, Moradkhani et al. (2005b) proposed a dual-state estimation approach based on the EnKF method for sequential estimation of both parameters and state variables of a hydrologic model. Weerts and EI Serafy (2006) compared the capability of EnKF and particle filter (PF) methods to reduce uncertainty in the rainfall-runoff update and internal model state estimation for flooding forecasting purposes. Shi et al. (2014) presented multiple parameter estimation using multivariate observations via the ensemble Kalman filter (EnKF) for a physically based land surface hydrologic model. Fan et al. (2017a) developed two integrated approaches for hydrological data assimilation through combination of ensemble Kalman filter and particle filter methods. However, due to the local complex characteristics of the watershed, some parameters in the hydrologic model may be not quite identifiable and showed slow convergence (Moradkhani et al., 2005b, 2012). Such unidentifiable parameters would lead to extensive uncertainties in hydrologic forecasts. Moreover, to prevent the ensemble collapse in EnKF (i.e. all ensembles being essentially the same), stochastic perturbations would usually be added in the EnKF updating process, leading to some extent of uncertainties, even after long time data assimilation process, in the parameters of hydrologic models. Consequently, Fan et al. (2015b) proposed a coupled ensemble filtering and probabilistic collocation (EFPC) approach is proposed for uncertainty quantification of hydrologic models. In the proposed EFPC, the EnKF method would be employed to approximate the posterior probabilities of model parameters and improve the forecasting accuracy based on the observed measurements, while the PCM approach is proposed to construct a model response surface in terms of the posterior probabilities of model parameters to reveal uncertainty propagation from model parameters to model outputs.

Another sequential data assimilation approach includes sequential Monte Carlo (SMC) methods such as particle filter (PF) (Arulampalam et al., 2002; Moradkhani et al., 2005a; Weerts and El Serafy, 2006; Noh et al., 2011; Plaza et al., 2012). Similar to EnKF, particle filtering evolves a sample of the state space forward using the SMC method to approximate the predictive distribution, but it is potentially more computational expensive than EnFK (Liu et al., 2012). The most significant advantage that $\mathrm{PF}$ outperforms EnKF is the relaxation of Gaussian distribution in state-space model errors. Furthermore, the PF method performs updating on the particle weights instead 
of the state variables, which can reduce numerical instability especially in physically-based or process-based models (Liu et al., 2012). The initial implementation of PF was based on sequential importance sampling, which would lead to severe deterioration for particles (i.e. only several or even on particle would be available). Consequently, sampling importance resampling (SIR) could be used (Moradkhani et al., 2005a) was then developed to mitigate the above problem. Previous studies in other fields concluded that the PF method usually requires more samples than other filtering methods and the sample size would increase exponentially with the size of state variables (Liu and Chen, 1998; Snyder et al., 2008; Fearnhead and Clifford, 2003). Specifically, hundreds or thousands of ensemble members may be needed for reliable characterization of the posterior PDFs even for small problems with only a few unknown states and parameters (Liu et al., 2012). The study proposed by Weerts and El Serafy (2006) showed that, for conceptual hydrologic models, PF would perform better than EnKF when the sample size is more than a hundred. However, the number requirement of particles for physically-based distributed hydrologic models may limit operational applications of PF (Liu et al., 2012). Recent improvement for PF is to combine the strengths of sequential Monte Carlo sampling and Markov chain Monte Carlo simulation and is especially designed for treatment of forcing, parameter, model structural and calibration data error (Moradkhani et al., 2012; Vrugt et al., 2013). Such an integration can allows for a more complete representation of the posterior distribution, reducing the chance of sample impoverishment and leading to a more accurate streamflow forecast with small, manageable ensemble sizes (Moradkhani et al., 2012). Recently, Fan et al. (2017b) proposed a copula-based particle filter (CopPF) approach for sequential hydrological data assimilation by considering parameter correlation structures. In CopPF, multivariate copulas are proposed to reflect parameter interdependence before the resampling procedure with new particles then being sampled from the obtained copulas. The proposed method can provide more accurate results for both deterministic and probabilistic predicttion with small sample size scenarios. In order to further explore uncertainty propagation in hydrologic simulation, Fan et al. (2016c) proposed a hybrid sequential data assimilation and probabilistic collocation (HSDAPC) approach, in which the model parameters are first quantified by a particle filter method, and a probabilistic collocation method (PCM) is further employed to show uncertainty propagation from model parameters to model outputs, and characterize the temporal dynamics of parameter sensitivities to the predictive uncertainties.

\section{Conclusions}

In the past decades, a large number of research efforts were made in uncertainty quantification and reduction for hydrologic models. These approaches mainly focus on parameter uncertainties (e.g. MCMC), model structural uncertainties (e.g. BMA), as well as model states (e.g. data assimilation). However, some issues are still needed to be explored.

1) Currently, many efforts have been conducted to explore efficient uncertainty quantification methods for hydrolo- gic models. However, these methods seldom consider parameter interdependence and thus may lead to low sample evolution efficiency. Thus, one potential way to achieve efficient uncertainty quantification is to introduce multivariate statistical approaches (e.g. copula) into MCMC to reflect parameter interdependence and then enhance sampling efficiency.

2) For generic hydrologic predictions, there are uncertainties embodied in inputs, model structures, parameters and outputs. However, most studied mainly focused on quantifying uncertainties from one of those three sources. There are seldom studies to comprehensively explore both individual and interactive effects of all the three sources. Moreover, no studies have ever reported to characterize which source would make the greatest contribution to the resulting uncertainties of the hydrologic forecasts. Consequently, further studies are required to comprehensively explore the single and interactive effects of uncertainty sources and further identify major or dominant uncertainty sources. This is quietly meaningful for exploring the efficient ways to improve the predictability of hydrological models.

Acknowledgments. This research was supported by the National Key Research and Development Plan (2016YFA0601502). The author is very grateful for the editor's and the anonymous reviewers' insightful and constructive comments. They are critically helpful for improving this manuscript.

\section{References}

Abba, S.I., Sinan, J.H., and Jazuli, A. (2017). River water modelling prediction using multi-linear regression, artificial neural net- work, and adaptive neuro-fuzzy inference system techniques. Procedia Computer Science, 120, 75-82. https://doi.org/10.1016/j.procs.201 7.11.212.

Abbott, M.B., Bathurst, J.C., Cunge, J.A., O'Connel, P.E., and Rasmussen, J. (1986a). An introduction to European hydrological system-systeme hydrologique European, "SHE", 1: History and philosophy of a physically-based distributed modeling system. Journal of Hydrology, 87, 47-59. https://doi.org/10.1016/0022-1694 (86)90114-9.

Abbott, M.B., Bathurst, J.C., Cunge, J.A., O'Connel, P.E., and Rasmussen, J. (1986b). An introduction to European hydrological system - Systeme Hydrologique European, "SHE", 1: Structure of a physically-based Distributed modeling system. Journal of Hydrology, 87, 61-77. https://doi.org/10.1016/0022-1694(86)90115-0.

Adamowski, J., Chan, H.F., Prasher, S.O., Ozga-Zielinski, B., and Sliusarieva, A. (2012). Comparison of multiple linear and nonlinear regression, autoregressive integrated moving average, artificial neural network, and wavelet artificial neural network methods for urban water demand forecasting in Montreal, Canada. Water Resources Research, 48, W01528. https://doi.org/10.1029/2010W R009945.

Adamowski, J. and Karapataki, C. (2008). Comparison of multivariate regression and artificial neural networks for peak urban water demand forecasting: the evaluation of different ANN learning algorithms. Journal of Hydrologic Engineering (ASCE), 15(10), 729-743. https://doi.org/10.1061/(ASCE)HE.1943-5584.0000245

Allataifeh, N. (2013). Uncertainties in Hydrological Models. Term Project Report, School of Engineering, University of Guelph. 
Arulampalam, M.S. (2002). A tutorial on particle filters for online nonlinear/non-Gaussian Bayesian tracking, IEEE Transactions on Signal Process, 50, 174-188. https://doi.org/10.1109/78.978374.

Bates, J.M. and Granger, C.W.J. (1969). The combination of forecasts. Operations Research Quarterly, 20, 451-468. https://doi.org/10. 1057/jors. 1969.103.

Beven, K.J. (1985). Chapter 13, Distributed Models, in Anderson, M.G. and Burt, T.P. (Eds.), Hydrologic Forecasting, Wiley, New York.

Beven, K.J. (2001). Rainfall-runoff modeling - The primer, Wiley, Chichester, UK

Beven K.J. and Binley, A.M. (1992). The future of distributed models: model calibration and uncertainty in prediction, Hydrological Processes, 6, 279-298. https://doi.org/10.1002/hyp.3360060305.

Beven K.J. and Kirkby, M.J. (1979). A physically based, variable contributing area model of basin hydrology, Hydrologic Sciences Bulletin, 24, 1-3. https://doi.org/10.1080/02626667909491834.

Boyle, D.P., Gupta, H.V., and Sorooshian, S. (2000). Toward improved calibration of hydrologic models: Combining the strengths of manual and automatic methods. Water Resources Research, 36(12), 3663-3674. https://doi.org/10.1029/2000WR900207.

Brutsaert, W. and Palange, M.B. (1998). Hydrologic cycle explains the evaporation paradox, Nature, 396, 30. https://doi.org/10.1038/23845.

Buckland, S.T., Burnham, K.P., and Augustin N.H. (1997). Model selection: an integral part of inference, Biometrics, 53, 603-618. https://doi.org/10.2307/2533961.

Burnash, R.J.C. (1995). The NWS river Forecast System-Catchment Modeling, in Singh, V. P. (Eds.), Computer Models of Watershed Hydrology, Water Resources - Publications, Highlands Ranch, CO, pp. 311-366.

Burnham, K.P. and Anderson D.R. (2002). Model Selection and Multimodel Inference: a practical information-theoretic approach, 2nd $e d s$, Springer, New York

Calver, A. and Wood, W.L. (1995). The institute of hydrology distributed model, in Singh, V. P. (Ed.), Computer Models of Watershed Hydrology, Water Resources - Publications, Highlands Ranch, CO, pp. 595-626.

Cigizoglu, H.K. (2005). Generalized regression neural network in monthly flow forecasting, Civil Engineering and Environmental Systems, 22(2),71-84. https://doi.org/10.1080/10286600500126256.

Clarke, R.T. (1973). A review of mathematical models used in hydrology, with some observations on their calibration and use. Journal of Hydrology, 19, 1-20. https://doi.org/10.1016/00221694 (73)90089-9.

Deb, K., Pratap A., Agarwal S., and Meyarivan T. (2002). A fast and elitist multiobjective genetic algorithm: NSGA-II. IEEE Transactions on Evolutionary Computation, 6(2), 182-197. https://doi.org/ $10.1109 / 4235.996017$.

DeChant, C.M. (2014). Quantifying the Impacts of Initial Condition and Model Uncertainty on Hydrologic Forecasts, Ph.D. Dissertation, Portland State University, Portland, United States.

Diks, C.G.H. and Vrugt J.A. (2010). Comparison of point forecast accuracy of model averaging methods in hydrologic applications. Stochastic Environmental Research and Risk Assessment, 24, 809820. https://doi.org/10.1007/s00477-010-0378-z.

Duan, Q., Sorooshian, S., and Gupta, V.K. (1992). Effective and efficient global optimization for conceptual rainfall-runoff models. Water Resources Research, 28(4), 1015-1031. https://doi.org/10. 1029/91WR02985.

Duan, Q.Y., Ajami, N.K., Gao, X.G., and Sorooshian S. (2007). Multimodel ensemble hydrological prediction using Bayesian model averaging, Advances in Water Resources, 30, 1371-1386. https://doi.org /10.1016/j.advwatres.2006.11.014.

Evensen, G. (1994). Sequential data assimilation with a non-linear quasigeostrophic model using Monte Carlo methods to forecast error statistics, Journal of Geophysical Research, 97, 905-924.
Fan, Y.R., Huang, G.H., Baetz, B.W., Li, Y.P., and Huang, K. (2017b). Development of copula-based particle filter (CopPF) approach for hydrologic data assimilation under consideration of parameter interdependence, Water Resources Research, 53 (6), 4850-4875, https://doi.org/10.1002/2016WR020144.

Fan, Y.R., Huang, G.H., Baetz, B.W., Li, Y.P., Huang, K., Chen, X. and Gao, M. (2017a). Development of integrated approaches for hydrological data assimilation through combination of ensemble kalman filter and particle filter methods, Journal of Hydrology, 550, 412-426. https://doi.org/10.1016/j.jhydrol.2017.05.010.

Fan Y.R., Huang, G.H., Li, Y.P., Wang, X.Q., and Jin, L. (2016a). Development of PCA-based cluster quantile regression (PCA-CQR) framework for streamflow prediction: Application to the Xiangxi River Watershed, China, Applied Soft Computing, 51, 280-293. https://doi.org/10.1016/j.asoc.2016.11.039.

Fan Y.R., Huang, G.H., Li, Y.P., Wang, X.Q., and Li Z. (2016b). Probabilistic prediction for monthly streamflow through coupling stepwise cluster analysis and quantile regression methods. Water Resources Management, 30(14), 5313-5331. https://doi.org/10.100 7/s11269-016-1489-1.

Fan Y.R., Huang, G.H., Baetz, B.W., Li, Y.P., Huang, K., Li, Z., Chen, X., and Xiong, L.H. (2016c). Parameter uncertainty and temporal dynamics of sensitivity for hydrologic models: a hybrid sequential data assimilation and probabilistic collocation method. Environmental Modelling and Software, 86, 30-49. https://doi.org/10.1016/ j.envsoft.2016.09.012.

Fan Y.R., Huang, W., Huang, G.H., Li, Z., Li, Y.P., Wang, X.Q, and Jin, L. (2015a). A stepwise-cluster forecasting approach for monthly streamflows based on climate teleconnections. Stochastic Environmental Research and Risk Assessment, 29(6), 1557-1569. https:// doi.org/10.1007/s00477-015-1048-y.

Fan Y.R., Huang, W.W., Huang, G.H., Li, Y.P., and Huang K. (2015b). A coupled ensemble filtering and probabilistic collocation approach for uncertainty quantification of hydrological models. Journal of Hydrology, 530, 255-272.https://doi.org/10.1016/j.jhydrol.2015.09. 035.

Fearnhead, P. and Clifford, P. (2003). On-line inference for hidden Markov models via particle filters, Journal of Royal Statistical Society Series B, Methodology, 65, 887-899. https://doi.org/10. 1111/1467-9868.00421.

Food and Agriculture Organization of the United Nations (FAO), Review of World Water Resources by Country, Rome, 2003.

Gao, H., Tang, Q., Shi, X., Zhu, C., Bohn, T.J., Su, F., and Wood, E.F. (2010). Water budget record from Variable Infiltration Capacity (VIC) model. Algorithm Theoretical Basis Document for Terrestrial Water Cycle Data Records.

Georgakakos, K.P. (1986a). A generalized stochastic hydrometeorological model for flood and flash flood forecasting. 1 Formulation, Water Resources Research, 22, 2083-2095. https://doi.org/10.102 9/WR022i013p02083.

Georgakakos, K.P. (1986b). A generalized stochastic hydrometeorological model for flood and flash-flood forecasting: 2 . Case studies, Water Resources Research, 22, 2096-2106. https://doi.org/10.102 9/WR022i013p02096.

Gupta, V.K., Sorooshian, S., and Yapo, P.O. (1998). Towards improved calibration of hydrological models: multiple and noncomensurable measures of information, Water Resources Research, 34, 751-763. https://doi.org/10.1029/97WR03495.

Masaki, Y., Schewe, J., Stacke, T., Tessler, Z.D., Wada, Y., and Wisser, D. (2014). Global water resources affected by human interventions and climate change, Proceedings of the National Academy of Science of the United States of America, 111(9), 3251-3256. https: //doi.org/10.1073/pnas.1222475110.

Hagemann, S., Chen, C., Clark, D.B., Folwell, S., Gosling, S.N., Haddeland, I., Hanasak, i N., Heinke, J., Ludwig, F., Voss, F., and Wiltshire, A.J. (2013). Climate change impact on available water 
resources obtained using multiple global climate and hydrology models. Earth System Dynamics, 4, 129-144. https://doi.org/10. 5194/esd-4-129-2013.

Haghighatjou, P., Akhoond-Ali, A.M., Behnia, A., and Chinipardaz, R. (2008). Parametric and nonparametric frequency analysis of monthly precipitation in Iran, Journal of Applied Sciences, 8, 32423248. https://doi.org/10.3923/jas.2008.3242.3248.

Hansen, B.E. (2007). Least-squares model averaging, Econometrica, 75, 1175-1189. https://doi.org/10.1111/j.1468-0262.2007.00785.x.

Hansen, B.E. (2008). Least-squares forecast averaging, Journal of Econometrics, 146, 342-350. https://doi.org/10.1016/j.jeconom.20 08.08.022.

Hoeting, J.A., Madigan, D., Raftery, A.E., and Volinsky, C.T. (1999). Bayesian model averaging: a tutorial, Statistical Science, 14, 382417. https://doi.org/10.1214/ss/1009212519.

Holland, J. (1975) Adaptation in Natural and Artificial Systems, University of Michigan Press, Ann Arbor, Mich.

Julier, S.J. and Uhlmann, J.K. (1997). A new extension of the Kalman filter to nonlinear systems, Proceedings of SPIE, 3068, 182-193. https://doi.org/10.1117/12.280797.

Kalman, R. E. (1960). A new approach to linear filtering and prediction problems, Transactions of the ASME-Journal of Basic Engineering, 82, 35-45, 1960. https://doi.org/10.1115/1.3662552.

Kite, G.W. (1995). Scaling of input data for macroscale hydrologic modeling, Water Resources Research, 31(11). 2769-2781. https:// doi.org/10.1029/95WR02102.

Kuczera, G., and Parent, E. (1998). Monte Carlo assessment of parameter uncertainty in conceptual catchment models. The Metropolis algorithm, Journal of Hydrology, 211, 69-85. https://doi.org/ 10.1016/S0022-1694(98)00198-X.

Li, Z., Huang, G.H., Wang, X.Q., Han, J.C., and Fan, Y.R. (2016). Impacts of future climate change on river discharge based on hydrological inference: A case study of the Grand River Watershed in Ontario, Canada, Science of The Total Environment, 548, 198210. https://doi.org/10.1016/j.scitotenv.2016.01.002

Li, Z., Huang, G.H., Han, J.C., Wang, X.Q., Fan, Y.R., Cheng, G.H., Zhang, H., and Huang, W., (2015). Development of a stepwiseclustered hydrological inference model, Journal of Hydrologic Engineering, 20(10), 04015008. https://doi.org/10.1061/(ASCE)H E.1943-5584.0001165.

Liu, J.S. and Chen, R. (1998). Sequential Monte Carlo methods for dynamic systems, Journal of the American Statistical Association, 93, 1032-1044. https://doi.org/10.1080/01621459.1998.10473765.

Liu, L.R., Huang, C.Z., Huang, G., Baetz, B.W., and Pittendrigh, S.M. (2018a). How a carbon tax will affect an emission-intensive economy: A case study of the Province of Saskatchewan, Canada. Energy, 159, 817-826. https://doi.org/10.1016/j.energy.2018.06.163.

Liu, L.R., Huang, G., Baetz, B.W., Huang, C.Z., and Zhang, K.Q. (2018b). A factorial ecologically-extended input-output model for analyzing urban GHG emissions metabolism system. Journal of cleaner production, 200, 922-933. https://doi.org/10.1016/j.jclepro. 2018.07.298

Liu, Y. and Gupta, H.V. (2007). Uncertainty in hydrologic modelling: Toward an integrated data assimilation framework, Water Resources Research, 43, W07401. https://doi.org/10.1029/2006WR005756.

Liu, Y., Weerts, A.H., Clark, M., Hendricks, Franssen, H.J., Kumar, S., Moradkhani, H., Seo, D.J., Schwanenberg, D., Smith, P., van Dijk, A.I.J.M., van Velzen, N., He, M., Lee, H., Noh, S.J., Rakovec, O., and Restrepo, P. (2012). Advancing data assimilation in operational hydrologic forecasting: progresses, challenges, and emerging opportunities, Hydrology and Earth System Sciences, 16, 38633887. https://doi.org/10.5194/hess-16-3863-2012.

Mantovan, P. and Todini, E. (2006). Hydrological forecasting uncertainty assessment: Incoherence of the GLUE methodology, Journal of Hydrology, 330(1-2), 368-381. https://doi.org/10.1016/j.jhydrol. 2006.04.046.
Montanari, A. and Brath, A., (2004). A stochastic approach for assessing the uncertainty of rainfall-runoff simulations, Water Resources Research, 40, W01106. https://doi.org/10.1029/2003WR 002540.

Moor, R.J. (1985). The probability-distributed principle and runoff production at point and basin scales, Hydrological Sciences Journal, 30, 273-297. https://doi.org/10.1080/02626668509490989.

Moor, R.J. (2007). The PDM rainfall-runoff model, Hydrology \& Earth System Sciences, 11(1), 483-499. https://doi.org/10.5194/hess -11-483-2007.

Moradkhani, H., Dechant, C.M., and Sorooshian, S. (2012). Evolution of ensemble data assimilation for uncertainty quantification using the particle filter-Markov chain Monte Carlo method, Water Resources Research, 48, W12520. https://doi.org/10.1029/2012WR 012144.

Moradkhani, H., Hsu, K., Gupta, H.V., and Sorooshian, S. (2005a). Uncertainty asssessment of hydrologic model states and parameters: sequential data assimilation using particle filter, Water Resources Research, 41, W05012. https://doi.org/10.1029/2004WR003604.

Moradkhani, H., Sorooshian, S., Gupta, H.V., and Houser, P. (2005b) Dual state-parameter estimation of hydrologic models using ensemble Kalman filter, Advances in Water Resources, 28, 135-147. https://doi.org/10.1016/j.advwatres.2004.09.002.

Moradkhani, H. and Sorooshian, S. (2008). General review of rainfallrunoff modeling: Model calibration, data assimilation and uncertainty analysis, in Sorooshian, S., Hsu, K.L., Coppola, E., Tomassetti, B., Verdecchia, G., and Visconti G. (Eds.), Hydrological Modelling and the Water Cycle: Coupling the Atmospheric and Hydrologic Models, Springer, Berlin.

Nakayama, T. and Shankman, D. (2013). Impact of the Three-Gorges Dam and water transfer project on Changjiang floods, Global and Planetary Change, 100, 38-50. https://doi.org/10.1016/j.gloplacha. 2012.10.004.

Noh, S.J., Tachikawa, Y., Shiiba, M., and Kim, S. (2011). Applying sequential Monte Carlo methods into a distributed hydrologic model: lagged particle filtering approach with regularization, Hydrology and Earth System Sciences, 15, 3237-3251. https://doi. org/10.5194/ hess-15-3237-2011.

Okkan, U. and Serbes, Z.A. (2012). Rainfall-runoff modeling using least squares support vector machines, Environmetrics, 23, 549-564. https://doi.org/10.1002/env.2154.

Piao, S., Ciais, P., Huang, Y., Shen, Z., Peng, S., Peng, S., Li, J., Zhou, L., Liu, H., Ma, Y., Ding, Y., Friedlingstein, P., Liu, C., Tan, K., Yu, Y., Zhang, T., and Fang, J. (2010). The impacts of climate change on water resources and agriculture in China, Nature, 676, 43-51. https://doi.org/10.1038/nature09364.

Plaza, D.A., De Keyser, R., De Lannoy, G.J. M., Giustarini, L., Matgen, P., and Pauwels, V.R.N. (2012). The importance of parameter resampling for soil moisture data assimilation into hydrologic models using the particle filter, Hydrology and Earth System Sciences, 16, 375-390. https://doi.org/10.5194/hess-16-3752012

Raftery, A.E., Madigan, D., and Hoeting, J.A. (1997). Bayesian model averaging for linear regression models, Journal of the American Statistical Association, 92, 179-191 https://doi.org/10.1080/016214 59.1997.10473615.

Raftery, A.E., Gneiting, T., Balabdaoui, F., and Polakowski, M. (2005). Using Bayesian model averaging to calibrate forecast ensembles, Monthly Weather Review, 133, 1155-1174. https://doi.org/10.1175/ MWR2906.1.

Refsgaard, J.C. and Storm, B. (1995). MIKE SHE, in Singh, V. J. (Ed.), Computer Models in Watershed Hydrology, Water Resources Publications.

Reichle, R., Mclaughlin, D., and Entekhabi, D. (2002). Hydrologic data assimilation with the ensemble Kalman filter, Monthly Weather Review, 130(1), 103-114. https://doi.org/10.1175/1520-0493(2002) 
130<0103:HDAWTE>2.0.CO;2.

Renard, B., Kavetski, D., Kuczera, G., Thyer, M., and Franks, S. W. (2010). Understanding predictive uncertainty in hydrologic modeling: The challenge of identifying input and structural errors, Water Resources Research, 46, W05521. https://doi.org/10.1029/2009WR 008328

Price, W.L. (1987). Global optimization algorithms for a CAD workstation, Journal of Optimization Theory and Applications, 55(1), 133-146, 1987. https://doi.org/10.1007/BF00939049.

Sachindra, D.A., Huang, F., Barton, A., and Perera, B.J.C. (2013). Least square support vector and multi-linear regression for statistically downscaling general circulation model outputs to catchment streamflows, International Journal of Climatology, 33, 1087-1106. https://doi.org/10.1002/joc.3493,

Sadegh, M. and Vrugt, J.A. (2013). Bridging the gap between GLUE and formal statistical approaches: approximate Bayesian computation, Hydrology and Earth System Sciences, (17), 4831-4850. https://doi.org/10.5194/hess-17-4831-2013.

Sadeg, M. and Vrugt, J.A. (2014). Approximate Bayesian Computation using Markov Chain Monte Carlo simulation: DREAM (ABC), Water Resources Research, 50(8), 6767-6787. https:// doi.org/10.1002/2014WR015386.

Sadri, S. and Burn, D.H. (2012). Nonparametric methods for drought severity estimation at ungauged sites, Water resources Research, 48 , W12505. https://doi.org/10.1029/2011WR011323.

Scanlon, T.S., Caylor, K.K., Levin, S.A., and Rodriguez-Iturbe, I. (2007). Positive feedbacks promote power-law clustering of Kalahari vegetation, Nature, 449, 209-212. https://doi.org/10.1038/ nature06060.

Shi, Y., Davis, K.J., Zhang, F., Duffy, C.J., and Yu, X. (2014) Parameter estimation of a physically based land surface hydrologic model using the ensemble Kalman filter: A synthetic experiment, Water Resources Research, 50, 1-19. https://doi.org/10.1002/2013 WR014 070.

Smith, M.B., Seo, D., Koren, V.I., Reed, S.M., Zhang, Z., Duan, Q., Moreda, F., and Cong, S. (2004). The distributed model intercomparison project (DMIP): motivation and experiment design, Journal of Hydrology, 298, 4-26. https://doi.org/10.1016/j.jhydrol. 2004.03.040.

Solomon, S., Qin, D., Manning, M., Marquis, M., Averyt, K., Tignor, M.M.B., Miller Jr., H.L., and Chen, Z. (2007) Climate Change 2007: The Physical Science Basis, Cambridge University Press, Cambridge, 996 pp., 2007.

Song, P., Huang, G.H., An, C.J., Shen, J., Zhang, P., Chen, X.J., Shen, J., Yao, Y., Zheng, R.B., and Sun, C.X. (2018). Treatment of rural domestic wastewater using multi-soil-layering systems: Performance evaluation, factorial analysis and numerical modeling. Science of the Total Environment, 644, 536-546. https://doi.org/ 10.1016/ j.scitotenv. 2018.06.331

Sorooshian, S. and Gupta, V.K. (1995). Model calibration, in Singh, V.P. (Eds.), Computer Models of Watershed Hydrology, Water Resources Publications, Highlands Ranch, CO, pp. 23-67.

Sujay Raghavendra, N. and Deka, P.C. (2014). Support vector machine application in the field of hydrology: A review, Applied Soft Computing, 19, 371-386. https://doi.org/10.1016/j.asoc.2014.02.002.

Snyder, C., Bengtsson, T., Bickel, P., and Anderson, J. (2008). Obstacles to high-dimensional particle filtering, Monthly Weather Review, 136, 4629-4640. https://doi.org/10.1175/2008MWR2529.1.

Tang, Y., Reed, P., and Wagener, T. (2005). How effective and efficient are multi-objective evolutionary algorithms at hydrologic model calibration? Hydrology and Earth System Sciences, 10, 289-307. https://doi.org/10.5194/hess-10-289-2006.

Thiemann, M., Trosset, M., Gupta, H., and Sorooshian, S. (2001). Bayesian recursive parameter estimation for hydrological models, Water Resource Research, 37(10), 2521-2535. https://doi.org/10.10 29/2000WR900405.
Turan, E.M. and Yurdusev, A.M. (2009). River flow estimation from upstream flow records by artificial intelligence methods, Journal of Hydrology, 369, 71-77. https://doi.org/10.1016/j.jhydrol.2009.02. 004.

Vrugt, J.A., Diks, C.G.H., Gupta, H.V., Bouten, W., and Verstraten, J.M. (2005). Improved treatment of uncertainty in hydrologic modelling: Combining the strengths of global optimization and data assimilation, Water Resources Research, 41, W01017. https://doi.or g/10.1029/2004WR003059.

Vrugt, J.A., Gupta, H.V., Bouten, W., and Sorooshian, S. (2003). A Shuffled Complex Evolution Metropolis algorithm for optimization and uncertainty assessment of hydrologic model parameters, Water Resources Research, 39(8), 1201. https://doi.org/10.1029/2002WR 001642.

Vrugt, J.A. and Robinson, B.A. (2007). Improving evolutionary optimization from genetically adaptive multimethod search, Proceedings of the National Academy of Sciences, 104, 708-711. https://doi.org/10.1073/pnas.0610471104.

Vrugt, J.A. and Sadegh, M. (2014). Toward diagnostic model calibration and evaluation: Approximate Bayesian computation, Water Resources Research, 49(7), 4335-4345. https://doi.org/10.1002/ wrcr.20354.

Vrugt, J.A., ter Braak, C.J.F., Diks, C.G.H., and Schoups, G. (2013). Hydrologic data assimilation using particle Markov chain Monte Carlo simulation: Theory, concepts and applications, Advances in Water Resources, 51, 457-478. https://doi.org/10.1016/j.advwatres. 2012.04.002.

Wagener, T. and Gupta H.V. (2005). Model identification for hydrological forecasting under uncertainty, Stochastic Environmental Research and Risk Assessment, 19(6), 378-387. https://doi.org /10. 1007/s00477-005-0006-5.

Wang, W., Van Gelder, P.H., Vrijling, J.K., and Ma J. (2006). Forecasting daily streamflow using hybrid ANN model, Journal of Hydrology, 324, 383-399. https://doi.org/10.1016/j.jhydrol.2005. 09.032 .

Wang, W.C., Chau, K.W., Cheng, C.T., and Qiu, L. (2009). A comparison of performance of several artificial intelligence methods for forecasting monthly discharge time series, Journal of Hydrology, 374, 294-306. https://doi.org/10.1016/j.jhydrol.2009. 06.019.

Wang, X.Q., Huang, G.H., Lin, Q.G., Nie, X.H., Cheng, G.H., Fan, Y.R., Li, Z., Yao, Y., and Suo M.Q. (2013). A stepwise cluster analysis approach for downscaled climate projection-A Canadian case study, Environmental Modelling \& Software, 49, 141-151. https://doi.org/10.1016/j.envsoft.2013.08.006.

Weerts, A.H. and El Serafy, G.Y.H. (2006). Particle filtering and ensemble Kalman filtering for state updating with hydrological conceptual rainfall-runoff models, Water Resources Research, 42, W09403. https://doi.org/10.1029/2005WR004093.

Wheater, H.S., Jakeman, A.J., and Beven, K.J. (1993). Progress and directions in rainfall-runoff modeling, in Jakeman, A.J., Beck, M.B., and McAleer, M.J. (Eds.), Modeling change in environmental systems, John Wiley \& Sons, Chichester, UK, pp. 101-132.

Wu, C.L. (2010). Hydrological predictions using data-driven models coupled with data preprocessing techniques, Ph.D. Dissertation, The Hong Kong Polytechnic University. https://doi.org/10.1029 /2007 WR006737.

Xie, X. and Zhang, D. (2013). A partitioned update scheme for stateparameter estimation of distributed hydrologic models based on the ensemble Kalman filter, Water Resources Research, 49, 7530-7365. https://doi.org/10.1002/2012WR012853.

Xie, Y.L., Xia, D.X., Ji, L., and Huang, G.H. (2018). An inexact stochastic-fuzzy optimization model for agricultural water allocation and land resources utilization management under considering effective rainfall. Ecological Indicators, 92, 301-311. https://doi.org /10.1016/j.ecolind.2017.09.026.

Zhang, J.L., Li, Y.P., Zeng, X.T., Huang, G.H., Li, Y., Zhu, Y., and Liu, 
J. (2019). Effluent trading planning and its application in water quality management: A factor-interaction perspective. Environmental research, 168, 286-305. https://doi.org/10.1016/j.envres.2018. 09.029

Zhao, R.J. (1992). The Xinanjiang model applied in China, Journal of Hydrology, 135(1-4), 371-381. https://doi.org/10.1016/0022-1694
(92)90096-E.

Zhuang, X.W., Li, Y.P., Nie, S., Fan, Y.R., and Huang, G.H. (2018). Analyzing climate change impacts on water resources under uncertainty using an integrated simulation-optimization approach, Journal of Hydrology, 556, 523-538. https://doi.org/10.1016/j.jhydrol. 2017.11.016. 